\title{
Are the nutritional guidelines for diabetics achievable?
}

\author{
BY MARGARET M. HUMPHREYS
}

\author{
Department of Nutrition and Dietetics, Cork University Hospital, Wilton, Cork, Republic of Ireland
}

Manipulation of dietary therapy as an adjunct to the management of diabetes mellitus was first recorded in the Ebers Papyrus in $1550 \mathrm{BC}$. The treatment then recommended was a $4 \mathrm{~d}$ course of a decoction of bones, wheat, grain, grit, green lead and earth. A review of dietary recommendations for subjects with diabetes illustrates that for centuries the relative roles of total energy intake, carbohydrate and fat have perplexed clinicians (Vinik \& Wing, 1990).

\section{CURRENT RECOMMENDATIONS}

The current dietary recommendations for people with diabetes (Table 1) are well established (Diabetes and Nutrition Study Group of the European Association for the Study of Diabetes (EASD), 1995), with the diabetic associations in developed countries offering similar advice (Nutrition Subcommittee of the British Diabetic Association's Professional Advisory Committee (BDA), 1992; American Diabetes Association, 1994). These proposals are also similar to those advocated for the Irish population (Health Promotion Unit, Department of Health, 1990), and the World Health Organization recommendations for Europe (James et al. 1988). The broad aims of dietary prescription for people with diabetes are first to abolish primary symptoms, second to minimize the long-term macrovascular and microvascular complications which together result in the morbidity and shortened life span associated with all types of diabetes.

\section{MACRONUTRIENT INTAKES}

It is well established that many people with diabetes frequently find dietary modification the most difficult aspect of their treatment (Lockwood et al. 1986). The current guidelines have now been applied clinically for over a decade, and several authors have reported actual nutrient intakes among various diabetic groups (Close et al. 1992; Shimakawa et al. 1993; Humphreys et al. 1994; Toeller et al. 1996). Comparisons of these results must, of course, be interpreted with caution due to the different methodologies employed. Nevertheless, some interesting trends are apparent.

\section{Protein}

The BDA (1992) currently recommend a protein intake of 10-15\% of total energy, and the EASD (1995) suggest 10-20\% of total energy. People with incipient nephropathy are recommended a protein intake of $0.7-0.9 \mathrm{~g} / \mathrm{kg}$ body weight (EASD, 1995). Protein intakes were either above or on the upper end of recommendations in the studies of Close et al. (1992), Shimakawa et al. (1993), Humphreys et al. (1994) and Toeller et al. (1996). When compared with the intakes of age-matched subjects in the general population, there were significantly higher protein intakes in all diabetic groups (Humphreys et al. 1994). In the Eurodiab study as reported by Toeller et al. (1996), the nutrient intakes of 2868 subjects with insulin-dependent diabetes mellitus are presented and it is of interest that $30 \%$ of all subjects studied had evidence of elevated albumin excretion rates. However, only four of these were found to have protein intakes of $0.8 \mathrm{~g} / \mathrm{kg}$ body weight or below. Protein tended 
Table 1. Summary of nutritional recommendations for people with diabetes (From Nutrition Subcommittee of the British Diabetic Association's Professional Advisory Committee, 1992)

\begin{tabular}{lc}
\hline \hline Energy & To approach BMI $22 \mathrm{~kg} / \mathrm{m}^{2}$ \\
Carbohydrate (\% of total energy) & $50-55$ \\
$\quad$ Added sucrose or fructose $(\mathrm{g} / \mathrm{d})$ & $<25$ \\
$\quad$ Dietary fibre $(\mathrm{g} / \mathrm{d})$ & $>30$ \\
Total fat (\% of total energy) & $30-35$ \\
Saturated fatty acids (\% of total energy) & $<10$ \\
Monounsaturated fatty acids (\% of total energy) & $10-15$ \\
Polyunsaturated fatty acids (\% of total energy) & $<10$ \\
Protein (\% of total energy) & $10-15$ \\
\hline
\end{tabular}

to come from predominantly animal sources (Humphreys et al. 1994; Toeller et al. 1996), a factor that may not be desirable in light of the evidence that this type of protein has a more adverse effect on kidney function than vegetable protein (Pendersen et al. 1990).

\section{Fat}

Atherosclerosis accounts for approximately $80 \%$ of all diabetic mortality (American Diabetes Association, 1989) and abnormalities of lipid and lipoproteins are frequently observed in diabetic subjects, especially those with poor metabolic control. Close et al. (1992) reported similar levels of fat intakes among diabetic and non-diabetic subjects; they also demonstrated a reciprocal relationship between the proportion of energy in the diet derived from fat and that from sugar. Shimakawa et al. (1993) reported a significantly higher fat intake among diabetic subjects, and in the Eurodiab study total fat intake contributed $38 \%$ of energy, with $14 \%$ from saturated fat. This high saturated-fat intake was reflected in all the studies.

\section{Carbohydrate}

All these papers found that carbohydrate intake was significantly below the $50-55 \%$ of total energy level, with Close et al. (1992) and Shimakawa et al. (1993) reporting intakes lower than those among control groups. In the Eurodiab study, no centre attained a level of $50 \%$ of total energy from carbohydrate or greater (Toeller et al. 1996), and among the Irish group (Humphreys et al. 1994) total carbohydrate intake was similar to that of the general population; however, subjects with diabetes consumed less sugars (glucose, fructose, galactose, sucrose and maltose) and significantly more starch and fibre. The mean carbohydrate intakes in these studies varied from 39 to $43 \%$ of total energy. Dietary fibre intakes were well below that recommended in each study and soluble fibre intakes were low (Close et al. 1992; Humphreys et al. 1994).

\section{INTERVENTION PROGRAMMES}

Having established that many diabetic patients do not achieve their recommended dietary targets, we investigated whether more regular dietary education and supervision could improve dietary knowledge, compliance and metabolic control (Humphreys et al. 1997). Thirty-three insulin-dependent diabetic patients were allocated, using random numbers, to 
receive either baseline standard advice or, in addition, three-monthly dietary reinforcement, including video and food demonstrations. Patients were followed up for 1 year. Seven patients failed to complete the study. Baseline characteristics of both patient groups were similar with respect to age, duration of diabetes, BMI, dietary knowledge assessed by a standardized questionnaire, dietary intake assessed by $7 \mathrm{~d}$ food record and low-glycated haemoglobin $\left(\mathrm{HbA}_{\mathrm{lc}}\right)$. After 12 months, dietary knowledge was significantly better in those reviewed three-monthly compared with those reviewed at baseline only. However, median intakes of protein, carbohydrate, sugars, total fat, saturated fat and fibre did not differ between the two groups. Median $\mathrm{HbA}_{1 \mathrm{c}}$ values were also similar $(8.0$ v. $7.6 \%$ total haemoglobin, NS). We concluded that three-monthly dietary review does not improve dietary compliance, despite improved dietary knowledge, reflecting the difficulty of altering established eating patterns. The landmark results of the intensive-therapy regimen of the Diabetes Control and Complications Trial (DCCT) were achieved by an expert team of diabetologists, nurses, dietitians, and behavioural specialists, and the time, effort and cost required were considerable. The resources to implement this type of programme are not widely available (Diabetes Control and Complications Trial Research Group, 1993). An intensive educational approach to dietary change in people with non-insulin-dependent diabetes (Campbell et al. 1990) showed an improvement in the composition of macronutrient intake, although this did not necessarily improve glycaemic control. Schlundt et al. (1994) outlined situational obstacles to dietary adherence for adults with diabetes, and a recent pilot study suggests that augmenting a standard behavioural treatment programme with a motivational component may significantly enhance adherence to programme recommendations and glycaemic control (Smith et al. 1997).

\section{DISCUSSION}

It has been shown that groups of people with diabetes do not achieve the quantitative dietary recommendations for diabetes, and it is unrealistic to expect that these recommendations will be achieved by all the people, all the time. The recommendations are not necessarily final, but rather, as stressed in the BDA (1992) guidelines, they are intended as 'pragmatic solutions to prevailing uncertainties, based on available evidence'. The quality of life of the individual must be considered when defining nutritional objectives (EASD, 1995), and the American Diabetes Association (1994) suggest that the recommended diet can only be defined as a dietary prescription based on nutrition assessment and treatment goals. The social and cultural importance of food, along with the many situational obstacles to eating behaviour, must be taken into account when attempting to change existing eating patterns. Gibney (1990) highlighted that success of a nutrition intervention programme must be measured in terms of nutritional end points. If the programme is related to some physiological index as an end point, then there should be a clear unequivocal relationship between the two without any confounding factors. Many of the studies relating to nutritional education among diabetics use metabolic control as indicated by $\mathrm{HbA}_{1 \mathrm{c}}$ as an end point. Nutrient intake, however, is clearly not the only factor which will influence $\mathrm{HbA}_{\mathrm{Ic}}$ among subjects with diabetes. More long-term studies with larger numbers are needed to assess the effectiveness of such intervention programmes.

\section{CONCLUSION}

The current dietary guidelines for people with diabetes were not achieved among the groups of diabetics examined. People with diabetes tended to consume less carbohydrate, 
and more fat and protein than their non-diabetic counterparts. Current nutritional guidelines for people with diabetes are similar to the dietary recommendations for the general population. All subjects should be able to make some improvement in their intake; however, it is unrealistic, and perhaps undesirable, to expect each person with diabetes to achieve the quantitative guidelines proposed.

\section{REFERENCES}

American Diabetes Association (1989). Consensus Statement: Role of cardiovascular risk factors in prevention and treatment of microvascular disease in diabetes. Diabetes Care 12, 573-579.

American Diabetes Association (1994). Nutritional recommendations and principles for people with diabetes mellitus. Journal of the American Dietetic Association 94, 504-506.

Campbell, L. V., Barth, R., Gosper, J. K., Jupp, J. J., Simons, L. A. \& Chrisholm, D. J. (1990). Impact of intensive educational approach to dietary change in NIDDM. Diabetes Care 13, 841-847.

Close, E. J., Wiles, P. G., Lockton, J. A., Walmsley, D., Oldham, J. \& Wales, J. K. (1992). Diabetic diets and nutritional recommendations: what happens in real life? Diabetic Medicine 9, 181-188.

Diabetes and Nutrition Study Group of the European Association for the Study of Diabetes (1995). Recommendations for the nutritional management of patients with diabetes mellitus. Diabetes Nutrition and Metabolism 8, 1-4.

Diabetes Control and Complications Trial Research Group (1993). The effect of intensive treatment of diabetes on the development and progression of long term complications in insulin dependent diabetes. New England Journal of Medicine 329, 977-986.

Gibney, M. J. (1990). Dietary guidelines: A critical appraisal. Journal of Human Nutrition and Dietetics 3, 245254.

Health Promotion Unit, Department of Health (1990). Framework for Action. Dublin: Nutrition Health Promotion, Department of Health.

Humphreys, M., Cronin, C. C., Barry, D. G. \& Ferriss, J. B. (1994). Are the nutritional recommendations for insulin dependent diabetic patients being achieved? Diabetic Medicine 11, 79-84.

Humphreys, M. M., Higgins, T. M., Barry, D. G. \& Ferriss, J. B. (1997). Does regular dietary reinforcement improve metabolic control in diabetic patients? Irish Joumal of Medical Science 116, Suppl. 1, 6-7.

James, W. P. T., Ferro-Luzzi, A., Izaksson, B. \& Szostak, W. B. (1988). Healthy Nutrition. WHO Regional Publication no. 24. Copenhagen: WHO.

Lockwood, D., Frey, M. L., Glandish, N. A. \& Hiss, R. G. (1986). The biggest problem in diabetes. Diabetes Educator 12, 30-33.

Nutrition Subcommittee of the British Diabetic Association's Professional Advisory Committee (1992). Dietary recommendations for people with diabetes: an update for the 1990s. Diabetic Medicine 9, 189-202.

Pendersen, M. M., Winther, E. \& Morgensen, C. E. (1990). Reducing protein in the diabetic diet. Diabetes and Metabolism 16, 454-459.

Schlundt, D. G., Rea, M. R., Kline, S. S. \& Pichert, J. W. (1994). Situational obstacles to dietary adherence for adults with diabetes. Journal of the American Dietetic Association 94, 874-879.

Shimakawa, T., Herrera-Acena, M. G., Colditz, G. A., Manson, J. E., Stampfer, M. J. \& Willett, W. C. (1993). Comparisons of diets of diabetic and non-diabetic women. Diabetes Care 16, 1356-1362.

Smith, D. E., Heckemeyer, C. M., Kratt, P. P. \& Manson, D. A. (1997). Motivational interviewing to improve adherence to a behavioural weight control programme for older obese women with NIDDM. Diabetes Care $20,52-54$.

Toeller, M., Kischan, A., Heifkamp, G., Shumacher, W., Milne, R., Buyken, A., Karamanor, B., Gries, F. A. \& the Eurodiab IDDM Complications Study Group (1996). Nutritional intake of 2868 IDDM patients from 30 centres in Europe. Diabetologia 39, 929-939.

Vinik, A. \& Wing, R. R. (1990). Nutritional management of the person with diabetes. In Diabetes Mellitus Theory and Practice, 4th ed., pp. 464495 [H. Rifkum and D. Porte, editors]. New York: Elsevier. 